University of California, Hastings College of the Law UC Hastings Scholarship Repository

Faculty Scholarship

1978

\title{
Computer-Aided Instruction in Law: Theories, Techniques, and Trepidations
}

Roger C. Park

UC Hastings College of the Law, parkr@uchastings.edu

Russell Burris

Follow this and additional works at: http://repository.uchastings.edu/faculty_scholarship

Part of the Legal Education Commons

\section{Recommended Citation}

Roger C. Park and Russell Burris, Computer-Aided Instruction in Law: Theories, Techniques, and Trepidations, 1978 Am. B. Found. Res. J. 1 (1978).

Available at: http://repository.uchastings.edu/faculty_scholarship/583

This Article is brought to you for free and open access by UC Hastings Scholarship Repository. It has been accepted for inclusion in Faculty Scholarship by an authorized administrator of UC Hastings Scholarship Repository. For more information, please contact marcusc@uchastings.edu. 


\title{
Computer-Aided Instruction in Law: Theories, Techniques, and Trepidations
}

\author{
Roger Park and Russell Burris
}

Legal education is only beginning to make use of the technological capabilities of computers as a medium for instructional design. In this article the authors show the applicability of computer-assisted instruction to law througb programmed instructional techniques. They trace the two decades of development of computer-assisted instruction (CAI) in law, the use and misuse of the computer's capabilities, the impact of CAI on law student attitudes and performance, and the positive student endorsement. They carefully analyze the computer's capacity for use in memory drills, tutorial sessions, and simulation exercises. They do not offer an unrestricted endorsement of the computer's capabilities but bope for the continuing development of CAI in the legal education process.

In a world where people are increasingly suspicious of and anxious about our dependence on sophisticated technology, the computer stands out as the awesome symbol of technological power. Can these machines replace the reflective subtlety of the human law teacher? Of course not. But we think they do have a role in legal education. The computer offers a unique opportunity to provide individualized instruction to students without altering the student-faculty ratio. There are dangers, however. Some computer-aided instruction (CAI) exercises do no more than

Roger Park is Professor of Law, University of Minnesota, and Affiliated Scholar, American Bar Foundation. A.B., Harvard, 1964; J.D., Harvard, 1969.

Russell Burris is Professor and Director, Consulting Group on Instructional Design, University of Minnesota. A.B., University of Colorado, 1949; Ph.D., Indiana University, 1958.

This article was undertaken as part of the American Bar Foundation Research Program in Legal Education. This program, under the direction of Felice J. Levine and Spencer L. Kimball, is advised by the $\mathrm{ABA}$ Special Committee for a Study of Legal Education (Ronald J. Foulis, Chairman; Thomas B. Curtis; R. W. Nahstoll; Christopher Otorowski; Edward F. Rodriguez, Jr.; Barbara W. Schwartz; Samuel D. Thurman).

The authors feel obliged to mention in this footnote the name of Alan Freeman, a colleague who read and rewrote the first six paragraphs of this article, thereby rendering himself responsible for any stylistic flaws therein. 
call for rote memorizing by students or reinforce the ever-present student tendency toward formalistic legal analysis. To some extent, these dangers are a function of computer technology itself, which calls for programming instructions that pigeonhole student answers into predetermined categories. However, they also stem from a narrow and questionable view of the learning process-a view that stresses "programming" of instruction so that the student is manipulated through discrete, logical steps accompanied by "reinforcement" of correct responses.

We believe that recent research in educational psychology has served to debunk this view of learning and cast doubt on the validity of exercises premised on that view. Accordingly, we urge CAI authors to break with that tradition and develop creative and challenging problems. The basic message of this article is that such problems can be developed (including ones that present debatable questions that cannot be resolved into categories of "correct" or "incorrect") and that they can be developed without inventing a science fiction computer that transcends current limits.

In Part I of this article, we describe the development of law-related programmed workbooks. As in other disciplines and professions, the roots of CAI in law can be found in the introduction of programmed instruction techniques during the late 1950s and early 1960s. Some of the current CAI authors began their experiments with workbooks and printed programmed instruction during this period; others have been at least influenced by those early efforts. We describe the design of these materials and the assumptions about human learning that influenced their design.

As programmed learning developed in other fields, researchers began to test those assumptions. At the conclusion of Part I, we comment upon these research findings and their implications for design of law-related CAI exercises.

In Part II we discuss whether computer-aided instruction in law can be useful within the limitations of current computer technology. We seek to describe some of the advantages of computer-aided instruction over printed material and suggest how computers can be used for simulations and "tutorials" that encourage students to exercise complex legal skills.

In Part III we briefly describe and evaluate attempts that have been made to measure the effectiveness of CAI as a method of law school instruction. At this early stage of development, these attempts have been tentative and incomplete, so we will be describing shortcomings and obstacles as well as some encouraging, but inconclusive, results. 


\section{THE DEVELOPMENT OF PROGRAMMED WORKBOOKS}

Several law professors experimented with printed programmed exercises in the 1960s. They include Robert J. Lynn, who produced a programmed lesson on the rule against perpetuities for use at Ohio State University College of Law in 1961; Thomas A. Wills, who produced materials on criminal law at the University of Miami School of Law; and Robert C. McClure, who has used programmed materials as the text in his Creditor's Remedies class at the University of Minnesota Law School since 1964. ${ }^{1}$ The most prolific supporter of programmed learning during this period was Charles D. Kelso of Indiana University School of Law. Kelso published his lengthy Programmed Introduction to the Study of Law, Part I: Case Skills in 1965 and wrote articles in the 1960 s explaining and advocating this method of instruction. ${ }^{2}$

Kelso's text uses programmed instruction to teach an introductory course in legal process. The program is designed to encourage active student participation throughout by requiring a written response to each segment of material. In the earlier parts of the text each segment or "frame" consists of one or a few sentences, and the student is required to respond to each frame with one or a few words. As the student progresses through the program, the frames, as well as the required responses, become more complicated. ${ }^{3}$

Kelso's text followed the principles of programmed instruction described by B. F. Skinner. ${ }^{4}$ Using Skinner's "linear programming" techniques, he produced a book that presented the subject to be learned in small segments or frames, thereby requiring the learner to progress through the material in a step-by-step process; all learners were required to go through the same sequence of steps. At each step the student is required to make an active response in the frame. This active participation contrasts with the more passive role of the learner in lectures or text reading. Before proceeding to the next step, the learner is expected

1. The programs by Professors Lynn, Wills, and McClure have not been published. Copies of these programs can be obtained by writing to their authors.

2. See Charles D. Kelso, Behavioral Psychology: Springboard for Imaginative Legal Educators, 45 Den. L.J. 313 (1968) [hereinafter cited as Behavioral Psychology] ; his Programming Shows Promise for Training Lawyers: A Report on an Experiment, $14 \mathrm{~J}$. Legal Educ. 243 (1961); and his Science and Our Teaching Methods: Harmony or Discord? $13 \mathrm{~J}$. Legal Educ. 183 (1960).

3. See appendix A for illustrative excerpts from Kelso's book.

4. Kelso specifically acknowledges his adherence to Skinner's principles in the preface to his programmed text. See Charles D. Kelso, Programmed Introduction to the Study of Law, Part I: Case Skills, Booklet, at iii (Indianapolis: Bobbs-Merrill Co., 1965). 
to make a correct response, in contrast with situations in which the learner is presented new material before mastery of earlier information has been achieved. The program was designed to permit the learner to proceed with few or no errors. Accordingly, material to be learned was presented in small steps, and hints, suggestions, and promptings appear within the frames. By offering the learner the correct answer for each frame, reinforcement in the form of confirming feedback was provided. The programs by Lynn and wills are similar both in format and in the assumptions made about processes involved in teaching and learning. The subject matter to be learned is presented in small segments as step-by-step frames, and the student is required to make an active response to each frame. The program aims to gradually shape the learner's behavior to achieve a critical performance level with few or no errors by arranging the information presented in small steps and in a logical sequence.

Under the view of programmed learning exemplified by these programs, the avoidance of errors is important for two reasons. First, any student error should not be practiced because, in order to correct that error, unlearning and relearning are required. Second, the student's response must be in agreement with the feedback at each frame to be reinforcing.

While McClure's programmed text in Creditor's Remedies presents the material to be learned in small steps and in a linear format, the approaches to eliciting the students' responses and providing feedback differ somewhat from the usual linear program. The learner is presented questions to be answered in a carefully constructed linear sequence, and for each question a reference to the particular part of the statute or case is provided as the means for the student to obtain feedback. The program itself does not provide the answers; students are expected to go to the cited authorities.

In 1972 Robert Keeton published his Programmed Problems in Insurance Law-a book very different from the others we have described. ${ }^{5}$ His program follows a "scrambled text" form described by Crowder ${ }^{6}$ as intrinsic programming. As an opponent of Skinnerian lin1972).

5. Robert Keeton, Programmed Problems in Insurance Law (St. Paul: West Publishing Co.,

6. See Norman Crowder, Automatic Tutoring by Intrinsic Programming, in A. Lumsdaine \& R. Glaser, eds., Teaching Machines and Programmed Learning: A Source Book (Washington, D.C.: National Education Association, Department of Audiovisual Instruction, 1960). 
ear programming, Crowder argued that a step-by-step sequence of the information to be learned, perfect for all learners, could not be constructed. It was necessary to create flexibility within and between steps in the program. By "within-step flexibility" he meant that, because of the complexity of the material and the complex differences among learners, a larger amount of information needed to be presented at each step. The "between-steps flexibility," or "branching," was essential so that the program could adjust to correct and incorrect responses. In his view avoidance of learner errors was not so important as correction of errors (which he described as "communication difficulties" between the program and the learner) by introducing special steps or repeating some steps.

The design of Keeton's book differs from Kelso's in several respects. Instead of attempting to develop knowledge in small, incremental steps by constant stimulus-response-reinforcement, it requires students to read substantial sections of unprogrammed text before beginning. Instead of using a linear program requiring students to fill in blanks, the book uses a branching program in which problems are presented and the student is asked to choose an answer from a multiplechoice format. ${ }^{7}$ After the student has chosen one of the responses, the program instructs him to proceed to another page of the workbook. The number of the page to which the student is sent frequently depends upon the answer that he gave to the original question. If the student gives an incorrect answer to the original question, he may be directed to a page containing a follow-up question designed to nudge him toward recognition of his error. After answering the follow-up question, the student may be directed to a page that tells him that his original answer was wrong, explains why it was wrong, suggests a review of a portion of the text if he is confused, and advises him to reanswer the original question.

Because of this branching feature, Keeton's workbook does not invariably send all students through the same sections of text. However, at some points Keeton's program asks students to choose from a multiple-choice format and then sends every student to the same page regardless of the answer given. The dialogue that follows the original question is intended to guide the student into changing the original answer if it was based upon a false proposition. For example, in Problem A the first question is, "Against whom, if anyone, does Hot Rod have a cause of

7. See appendix B for excerpts that illustrate Keeton's branching technique. 
action?" Six possible answers are offered, the final one being "Nobody." All students are directed to the second page, where they are asked

Do you agree with the following proposition?

... Because of legal restrictions against oral contracts of insurance, Hot

Rod has no valid claim against anyone.

After answering, students are directed to turn to the third page, which contains an explanation of why the proposition is incorrect and offers students the opportunity to change their original answer if it was based upon the incorrect proposition.

Keeton's insurance workbook, like much of law school teaching, permits and even invites students to make errors. When students give a correct answer to one of Keeton's questions, they are sometimes probed with a "distractor" question designed to see whether they have given the correct answer for the right reason. For example, the correct answer to Problem $\mathrm{K}$ is (a). If a student gives this answer, he is asked a further question:

Do you agree with the following proposition?

(c) Since Jones's name was the only name appearing on the face of the policy after the words "does insure," he was the only insured. Therefore, whatever rights Mortgagee Company has under the policy are derived from Jones's rights.

If, after considering this question, you wish to change your answer to (b) rather than (a), turn to page $\mathrm{K} 4$.

If you still believe (a) is the correct answer, turn to page $\mathrm{K} 3$. [If the student sticks with (a), his original answer, he is told that he is correct and informed why the "distractor" proposition is wrong.]

Some of the problems in Keeton's workbook contain several "distractors" before the student is told that his original answer was correct. This technique deviates drastically from the error-avoidance and immediate-reinforcement aspects of linear programming theory and makes the workbook more like Socratic class dialogue.

Another noteworthy example of written programmed instruction is Edward Kimball's recent workbook on Evidence. ${ }^{8}$ Kimball's approach

8. Edward Kimball, Problems in Evidence (unpublished ms. 1977). West Publishing Company is planning to publish Kimball's workbook in 1978. Also, Professor Kimball has recently submitted a manuscript describing classroom experiments involving his workbook to the Joumal of Legal Education for publication. Telephone conversation with Edward L. Kimball, Mar. 14, 1978. 
differs from that of his predecessors. His format is linear in the sense that it does not use branching or scrambled text. However, his book is radically different from the Skinner-inspired linear programs of the 1960s. Unlike the linear programs of Kelso, Lynn, and Wills, the Kimball program does not present learning material in small, incremental steps. Students are expected to read substantial textual assignments before beginning each chapter of the workbook. Nor is there an attempt to shape the learner's behavior with a program that will elicit minimal errors. The program's questions are often challenging and difficult. Also, the questions sometimes call for a long answer by the student, in contrast to linear programs designed to elicit one-word or short-phrase answers. Finally, feedback to students is often delayed for purposes of asking subordinate questions. When this occurs, the student is first asked a general question; then, before the author reveals his opinion about the answer, the student will be led through a series of subordinate questions that break the initial problem into elements and lead the student through an analysis of each element. For example, a general question inquiring about whether an evidentiary item should be excluded is sometimes followed by subordinate questions that explore the various inferences that can be drawn from the item and the alternative theories of admission.

In these respects, the instructional design of Kimball's workbook resembles that of Keeton's materials on insurance law. However, Kimball, unlike Keeton, completely avoids branching. He makes no attempt to gain the asserted advantages of individualized instruction provided by the "between-steps flexibility" advocated by Crowder. Every student, regardless of his answers, takes the same route through the program. This linear format is convenient because the student need not page forward and backward in order to follow the sequence of the program. It thereby minimizes the danger that a student will lose track of the author's train of thought during the initial study of the book's problems, and it facilitates review of the problems after the initial workthrough.

All the programmed materials we have described possess some common features. In spite of differences in the nature of the program-student dialogue, both linear and intrinsic programming stress the importance of establishing such a dialogue by requiring the student to make active or overt responses. Further, instead of merely presenting information or problems, both types of programs provide feedback so that the student is aware of progress. However, differences between the procedures prescribed for the construction of instructional programs by the 
proponents of the two types raise questions that present challenges to researchers concerned with understanding the processes of teaching and learning. During the 1960 s and 1970 s, many scholars sought to test theories of programmed learning with empirical research.

In summarizing much of this research, Wilbert McKeachie points out that most of the programming principles originally set forth by the early proponents of linear programs have not been supported by the research results. ${ }^{9}$ He points out that sequencing the information to be learned in small steps may be less effective than presenting it in larger chunks. ${ }^{10}$ Related to this is the finding by several researchers that immediate knowledge of results may be less effective than delayed feedback. ${ }^{11}$ The research results suggest that small steps with immediate feedback may have a detrimental effect on learning, especially in situations where the probability of error is low. It appears that frequent and immediate knowledge of results may cause the learner to be inattentive and careless. ${ }^{12}$ Some researchers have argued that delayed feedback is superior in situations that allow the learner a prefeedback opportunity to explore, organize, and rehearse the material to be learned and that provide informational feedback in contrast to mere acknowledgment of the correctness or incorrectness of the student's response. ${ }^{13}$

In drawing practical suggestions from these research results, McKeachie concludes that material to be learned should be presented in large steps and in a form that requires a response or otherwise challenges the student. ${ }^{14}$ That is, the author should create an error probability great enough to provide a challenge instead of seeking to avoid incorrect responses at all costs. Also, the informational aspect of the feedback given to the student should be stressed. If the response required is challenging enough to make errors likely, the informational dimension of feedback, rather than the dimensions of immediacy or

9. See Wilbert J. McKeachie, Instructional Psychology, 25 Ann. Rev. Psych. 183, 186 (1974).

10. See $i d$. at 186.

11. See Julius Sassenrath, Effects of Delay of Feedback and Length of Postfeedback Interval on Retention of Prose Material, 9 Psych. Schools 194-97 (1972); Persis Sturgis, Information Delay and Retention: Effect of Information in Feedback and Tests, $63 \mathrm{~J}$. Educ. Psych. 32-43 (1972); Richard Anderson, Raymond Kulhavy, \& Thomas Andre, Feedback Procedures in Programmed Instruction, $62 \mathrm{~J}$. Educ. Psych. 148-56 (1971).

12. See Anderson et al., supra note 11.

13. See Raymond Kulhavy \& Richard Anderson, Delay-Retention Effect with MultipleChoice Tests, 63 J. Educ. Psych. 505-12 (1972); E. Walker, Reinforcement-the One Ring, in J. L. Tapp, Reinforcement and Behavior (New York: Academic Press, 1969); W. K. Estes, Reinforcement in Human Behavior, 60 Am. Scientist 723-29 (1972).

14. See McKeachie, supra note 9, at 183. 


\section{confirmations of correctness, contributes to instructional effective- ness. ${ }^{15}$}

Perhaps more than anything else, the research results obtained in the 1960 s and early 1970 s pointed out the weaknesses and inadequacies of the science that deals with the processes involved in teaching and learning. The results obtained in the experiments were often equivocal in their implications for procedures to be followed in the construction of instructional programs. The research has pointed out the complex nature of the issues concerning how information might be presented so as to increase learning effectiveness. It is not possible to lay down a set of fixed ground rules that describe the optimal method of teaching all types of knowledge and skills.

However, the research does contain some results that should be encouraging to authors of programmed materials and computer-aided instruction. First, it lends support to the fundamental hypothesis of programmed instruction: that instruction requiring the student to respond actively is more effective than instruction allowing the student to play a passive role. ${ }^{16}$ Second, it suggests that feedback informing the student of any discrepancy between his response and the required one is desirable. ${ }^{17}$ Finally, it indicates that authors need not feel bound by the relatively rigid linear format that was the model for many of the earlier efforts at programmed instruction. ${ }^{18}$ Authors should feel free to experiment with techniques that they believe, on the basis of intuition

15. In the $1960 \mathrm{~s}$, many of the authors of programmed learning materials were influenced by the operant conditioning theories of behavioral psychology. Using the stimulus-response-reinforcement paradigm as the model of the human learning process, they tended to emphasize the importance of immediate reinforcement and avoidance of errors. In this decade, increased numbers of instructional researchers have expanded the focus of their efforts to include the cognitive processes associated with teaching and learning. In part, perhaps as a response to the uncertainty that seemed to result from the behaviorally oriented research of the 1960s, more attention was directed toward the processes of acquisition, memory, and problem solving involved in complex, higher-order human behavior. To be sure, Bruner and Ausubel had argued for consideration of cognitively oriented views early in the 1960 s, but their arguments had the greatest influence on the work of other researchers during the 1970s. See Jerome Bruner, Toward a Theory of Instruction (Cambridge, Mass.: Harvard University Press, 1966); David Ausubel, The Psychology of Meaningful Verbal Learning (New York: Grune and Stratton, 1963). Clearly, most current instructional research reflects a concern for how and under what conditions the learner is processing the information to be learned, what and how the information learned is retained in memory, and how the information is used in later performances; that is, attention has been focused on the cognitive rather than the exclusively behavioral aspects of teaching and learning.

16. See McKeachie, supra note 9, at 187.

17. See Raymond Kulhavy, Feedback in Written Instruction, 47 Rev. Educ. Res. 211-32 (1977).

18. See McKeachie, supra note 9 , at 187. 
or experience, will be most effective for teaching a given corpus of knowledge and skills.

\section{COMPUTER-AIDED INSTRUCTION}

Despite some earlier experiments, ${ }^{19}$ regular use of computer-aided instruction (CAI) in law schools did not begin until the early 1970s. Since then, computers at the University of Illinois College of Law, Champaign, and the University of Minnesota Law School have been programmed with a small but growing library of CAI exercises. In the 1977-78 school year, approximately 20 law schools are using these exercises for instructional purposes.

Development at the University of Illinois began in fall 1972, when Peter Maggs became interested in writing CAI after seeing a demonstration of nonlaw materials on the PLATO IV system. By 1973 Maggs was using a CAI exercise on offer and acceptance in his freshman contracts course, and a colleague, Thomas Morgan, had prepared an exercise on future interests. Both exercises have been continuously used in the Illinois instructional program since that time. ${ }^{20}$ Several other exercises, including material by Jane and Charles Kelso, have since been added to the Illinois system. ${ }^{2}$

Law-related CAI at the University of Minnesota began when Keeton spent the 1971-72 school year as a visiting professor at the university's law school. Keeton joined a faculty seminar conducted by Russell Burris, a psychologist who was the director of the university's Center for the Study of Programmed Learning, and he became interested in writing computer-aided instruction. With suggestions from Burris, he prepared an experimental version of a torts exercise. In 1972 Keeton returned to Harvard, where he continued to work on CAI to be programmed on the Minnesota system. By 1974 arrangements were made that allowed Keeton to use his exercises in his torts classes at

19. A demonstration of law-related CAI took place at the AALS conventions in 1965 and 1966 (see Kelso, Behavioral Psychology, supra note 2, at 333), but this material was never used in law school instruction. Subsequently the 1968 Committee on Teaching Methods of the AALS set out to create the first full-fledged CAI exercise on law. The result was an experimental civil procedure exercise by Arthur Miller, Layman Allen, and Prudence Abram. This exercise was demonstrated at a subsequent meeting of the AALS Teaching Methods section, and it is now available on the PLATO system of the University of Illinois.

20. See Peter Maggs \& Thomas Morgan, Computer-Based Legal Education at the University of Illinois: A Report of Two Years' Experience, 27 J. Legal Educ. 138, 144-52 (1975).

21. A current list of the exercises available on the PLATO system may be obtained from Professor Peter B. Maggs, University of Illinois College of Law (Champaign). 
Harvard. In the meantime, Roger Park joined the Minnesota faculty, took the Burris seminar, and prepared exercises on civil procedure and professional responsibility. These exercises have been used continuously as part of the instructional program at Minnesota since 1973. By January 1978 Minnesota-based exercises by Keeton and Park had been used by students at 14 law schools. ${ }^{22}$

The use of computers instead of workbooks brings about a number of differences in the nature of the student-program interaction. These differences raise new questions challenging our understanding of how to make teaching and learning more effective. Both the Minnesota and Illinois computer-based exercises make use, to a greater or lesser extent, of capabilities of the computer that cannot be duplicated in printed programmed learning. It is the capabilities and the issues of challenge that provide the focus in the following section.

\section{A. Special Capabilities of the Computer}

\section{Ability to Process the Student's Response}

The computer can recognize a large number of student responses, including the student's freely generated answers. It can be programmed to scan an answer typed in by the student and to look for key words (such as "hearsay") and to respond to those words if it finds them. Thus, when answers are sufficiently predictable, the author can avoid using a multiple-choice or yes/no format. Most of the existing computer exercises use the free-language capacity to some degree.

The free-language answer can, of course, also be used in workbooks. However, by using the computer, the author can combine freelanguage answers with branching, since the computer controls the matching of answers. For example, the computer can be programmed to recognize a variety of words-e.g., "best evidence," "hearsay," "leading question"-and to send students who give different answers into different branches. Branching could also be accomplished in the workbook format, but only at the cost of considerable inconvenience. It would be necessary to ask the student to turn the page, match up his own answer and a list of common answers, and then turn to another page to reach the beginning of the branch. This would be awkward. Moreover, because the student would see the most common answers (including the correct

22. A current list of the exercises available on the University of Minnesota computer may be obtained from Roger Park. 
answer) when matching up, the exercise would have a "leading" quality. Even without branching, the free-language capacity of the computer offers something that cannot be duplicated exactly in workbook form. The computer can tell the student that his answer is wrong and ask him to try again. The free-language workbook can only ask the student to compare his answer with the answer chosen by the workbook author.

Authors of law-related CAI have used various strategies to permit students to type free-language answers instead of choosing from a multiple-choice format. One method (used by Park and Keeton and perhaps others) is simply to ask the student to type in a free-language answer, and then to make his own comparison with an answer that the author has placed in the computer. For example, question 33 of Keeton's Child Injury-Torts exercise ${ }^{23}$ asks whether, as associate counsel for the plaintiff, the student would object to a proposed jury instruction. After the student answers, the computer asks for an explanation in 100 words or less. It records the student's answer for the instructor (and/or author) and then gives Keeton's answer. The computer does not attempt to evaluate the student's answer; the student is left to make the comparison.

This approach, although sometimes justified, obviously has its disadvantages and for that reason is rarely used. The principal advantages of using the computer-its branching and scoring capacity, the atmosphere of interaction that it creates-are lost when the computer merely collects the student's answer. Possibly the only advantage that the computer offers for this type of question is the capacity for speedier reporting of the student's answers and comments to authors and instructors. Unless the collected responses are used to improve the program or to provide the student with evaluative feedback, these advantages may be outweighed by the comparative cheapness and portability of written workbooks.

23. Robert E. Keeton, Child Injury-Torts (UMCC 1977).

At several points in this article (as here), we describe or quote from material that is in a computer's memory bank and that has not otherwise been published. In doing so, we will refer to the name of the computer exercise (here, "Child Injury-Torts") and the location of a computer in which the exercise is stored. Citations to UMCC refer to the University of Minnesota Computer Center; citations to PLATO-Illinois refer to the PLATO computer system at the University of Illinois.

Computer exercises are constantly being revised, so some of the language quoted from particular exercises may have been changed before or after the publication of this article. Except where otherwise noted, references to computer exercises refer to the exercises as they were in the fall of 1977. 
It is preferable, then, for the computer to respond specifically to the student's free-language answer. Park's Evidence (McCormick Version) exercise ${ }^{24}$ contains examples of this technique. In this exercise the student is asked to sustain or overrule an objection and then to justify his ruling. In the original version of the exercise, ${ }^{25}$ a student who sustained an objection received the following response from the computer:

You have ruled that the objection should be sustained. Please choose a reason for excluding the testimony from the following list:

1. Irrelevant/prejudicial

2. Best evidence rule

3. Leading question

4. Asks for opinion

5. Hearsay

6. Privilege

[Push "o" if you have changed your mind and want to overrule the objection.]

The words involved in the foregoing list are terms of art that are likely to appear in a lawyer's answer even if the lawyer were asked to explain in his own words the reasons for sustaining the objection. For example, there is apparently only one way to make a hearsay objection, and that is to use a sentence that contains the word "hearsay." So it proved feasible to eliminate the multiple-choice format and merely ask the question. The computer scans the student's answer for one of the listed words (hearsay) and certain common typographical errors (hearsya) or misspellings. Of course, it is not "thinking" about the answer in any way comparable to human thinking but merely scanning for words that it has been programmed to recognize. A few rules can be built into the system about interpretation of answers (e.g., ranking such recognizable words as "foundation" and "personal knowledge" if they are both contained in one answer), but basically the computer merely scans for key words. For that reason, it is useful to have the computer tell the student how it interprets his answer ("I read your answer as saying that the question is objectionable because it calls for a conclusion") before it responds to the answer, and perhaps to have the computer ask for confirmation as well ("Does this match with your answer?").

In the case of evidentiary objections, a vocabulary of 50 words

24. Roger Park, Evidence (McCormick Version) (UMCC 1978).

25. See Roger Park, Computer-Aided Exercises on Civil Procedure 115 (St. Paul: West Publishing Co., 1976) 
(with spelling variations) will prepare the computer to accept almost any answer that the student is likely to give. Of course, if an answer does not match, the computer can always retreat to a multiple-choice format, telling the student that it does not recognize his answer and is asking him to choose from a list. It will supply the CAI author with a list of nonmatching answers and the computer can be programmed to recognize these answers.

The use of free-language answers in an evidence exercise is easy because of the rather limited, specialized vocabulary that lawyers ordinarily use in order to make objections to testimony. In other situations, an unlimited invitation to give a free-language answer would be disastrous. One would not, for example, ask a student to distinguish two cases in an unlimited free-language format. The free-language format is a mistake if it leads either to misinterpretation of the student's answers or to student frustration because the computer constantly rejects answers on grounds that it has not been programmed to recognize them.

In many instances, it is necessary to limit the scope of a free-language answer. One way of limiting the answer is to instruct the student to revise a proposition offered by the computer. The following example from Keeton's Exercise on the Use of Intent in the Law of Torts ${ }^{26}$ illustrates this technique:

Question A8: In proposition A6, which is repeated below, which words must be changed to make the proposition correct?

Proposition A6: When Davis threw the water, he had the requisite state of mind for'battery on Jones if Davis should have known that the water was substantially certain to hit Jones and that the water was so dirty that the contact was substantially certain to be offensive to Jones.

As you answer, type only the words that must be changed.

[Student] : SHOULD HAVE KNOWN

[Computer]: As YAC [Your Amiable Computer] reads your answer, you receive full credit. Score: 7.75 points after 8 question(s).

Question A9: What word or words can be substituted for "should have known" to make proposition A6 correct?

[Student] : KNEW

[Computer]: As YAC reads your answer, you receive full credit. Score: 8.75 points after 9 questions. [Computer continues by explaining alternative correct answers:]

A similar limitation can be placed on answers by requiring students

26. Robert E. Keeton, Exercise on the Use of Intent in the Law of Torts (UMCC 1977). 
to complete a proposition that the computer has partially composed. Keeton's Intent exercise provides an example of this technique:

Question A5: Complete the following statement to make it entirely correct. (Your answer need not be all-inclusive. That is, it is sufficient to make a statement that is correct as to the set of circumstances it concerns. The statement need not cover all possible sets of circumstances.)

When he threw the water, Davis had the requisite state of mind for battery on Jones if Davis knew that Jones was walking below, and also knew ....

Numerous other methods can be used to limit the answers that the student can give to those that can be foreseen by the author. For example, the student can be asked to support a previous answer by quoting language from a case or statute or enumerating a statutory subsection. For example, the computer might instruct the student to "identify language in Smith $v$. Jones that supports your assertion that the court would have subject-matter jurisdiction. Type in the first two words of the sentence that you believe most strongly supports your position."

When feasible, free-language answers are often preferable to answers chosen from a multiple-choice format. First, free-language answers are less suggestive. One of the objectives of legal teaching is to develop the student's ability to generate appropriate terms and phrases in a variety of situations. When the student is confronted with a list of alternatives, he need not search his mind for an appropriate legal term. He may be able to choose from the list without learning to give a similar answer in the absence of a list, just as some persons develop proficiency in reading a foreign language without being able to speak it well.

The multiple-choice format also raises a danger of tempting the student into guessing or following hunches. The danger is enhanced when the student is confronted with a series of apparently mystifying choices after a difficult question. Instead of making an effort to reason through the problem, he may just push a button to keep going, either through impatience to finish or because he feels that after seeing the computer's response, he will be able to figure out the answer. Of course, the student's answer may not be a pure guess but the product of a half-formulated hunch or some cue other than the point that the author was attempting to make.

An example of a question that creates a high risk of temptation to guess is contained in Park's Jurisdiction and Venue exercise: ${ }^{27}$ 
Q-22. Why is the second quote preferable?

1. The second quote indicates that physical presence is a necessary condition for a change of domicile, whereas the first quote could be construed to mean that physical presence is merely a sufficient condition for change of domicile.

2. The second quote indicates that physical presence is a sufficient condition for change of domicile, whereas the first quote could be construed to mean that physical presence is merely a necessary condition for change of domicile. law.

3. The first quote states facts, whereas the second quote states a rule of law.

4. The second quote states facts, whereas the first quote states a rule of

A student who is not highly motivated is likely to choose one of these alternatives without fully puzzling out their consequences.

The free-language answer also avoids the danger of misleading the student with an ingenious multiple-choice question. Skinner describes this danger as follows:

[M] ultiple-choice material violates a basic principle of good programming by inducing the student to engage in erroneous behavior....

... Consider an item such as the following, which might be part of a course in high school physics:

As the pressure of a gas increases, volume decreases. This is because:

(a) The space between the molecules grows smaller

(b) The molecules are flattened

(c) etc. ...

Unless the student is as industrious and ingenious as the multiple-choice programmer, it will probably not have occurred to him that molecules may be flattened as a gas is compressed (within the limits under consideration). If he chooses item (b) and is corrected by the machine, we may say that he "has learned that it is wrong," but this does not mean that the sentence will never occur to him again. And if he is unlucky enough to select the right answer first, his reading of the plausible but erroneous answer will be corrected only "by implication"-an equally vague and presumably less effective process. In either case, he may later find himself recalling that "somewhere he has read that molecules are flattened when a gas is compressed." And, of course, somewhere he has. ${ }^{28}$

However, as we noted earlier, research has shown that errors do

28. See B. F. Skinner, Why We Need Teaching Machines, 31 Harv. Educ. Rev. 377,394 (1961), reprinted in A. de Grazia \& D. Sohn, Programs, Teachers, and Machines 61 (Bantam ed. 1964). 
not seem to persist in the manner that Skinner predicted. ${ }^{29}$ Moreover, whatever its validity in the situation described by Skinner, one may question whether his point is applicable to law teaching. One of the skills that law teachers seek to cultivate is the ability to resist spurious arguments. Law professors will sometimes play devil's advocate in order to develop this skill; casebook authors will sometimes include cases that are intended to hone students' critical faculties rather than impart knowledge about legal doctrine. If a computer exercise is to conduct an argumentative dialogue with a student, the author may have to take the risk of leaving some of them with the impression that the molecules are flattened.

\section{Ability to Respond Differentially to Student's Response}

The computer's ability to respond differentially permits more complex branching than is possible with printed programmed materials. To take a simple example, a computer can be programmed to send a student to question 25 if the student has given answer 3 to question 19 unless the student has also given answer 4 to question 24, in which case he should go to question 26. In a workbook, this sort of branching would have to be handled by telling the student to look back at previous pages to see what answers he gave, then to turn to a certain page if he has fulfilled all necessary conditions. After a few instructions such as the ones set forth above, the student would be ready to throw the workbook away.

Even for simpler branching, the workbook form can be irritating. If the author tries to develop a line of thought with several questions, the student may lose the train and have to retrace his steps by turning back to previous pages in the workbook. When branching is used, the pages will not be in sequence, so the student will have to skip back several pages to find the one needed. The computer can produce a transcript of the exercise as the student progresses through it. This transcript shows only questions on the branch that the student is exploring, so reference to previous questions and responses is very easy.

Moreover, the computer can handle a larger number of responses to each question. For example, it can ask, "Upon which exception(s) to the hearsay rule do you rely?" and accept, by name or number, any of the dozens of possible answers. A workbook would need a huge number of pages to provide concealed responses to each answer. 
The exercises make varying use of the branching capacity. Some hardly use it at all. For example, the Morgan exercise on future interests $^{30}$ is educationally similar to "linear" programming in workbook form. The student is asked to type in a word or words-e.g., "reversion" or "fee simple subject to a condition subsequent." In a linear workbook the student would uncover the author's answer and compare it with his own; in the Morgan exercise the computer tells whether the answer is right or wrong and gives the student a chance to try again. No explanation of wrong answers is given, and the student's path through the exercise does not vary according to the answers given, although the student is given a chance to review definitions by pushing the "HELP" key-the equivalent, in a workbook, of an instruction to review prior textual material if the student has missed a certain question.

Some exercises use branching extensively. Two of Park's evidence exercises are programmed so that the computer will recognize a correct answer and several wrong answers, responding to wrong answers either by telling the students why the answer is wrong or by asking questions designed to get them to recognize their error. ${ }^{31}$ Harbaugh's decisionmaking simulation places the student in the role of prosecutor and presents him with a large number of choices about action that can be taken. $^{32}$ The student's decisions control subsequent events in the simulation.

On the whole, computers seem superior to workbooks for exercises that require complex branching. Probably we can expect to see authors who use this technique turning to the computer, while workbook authors may increasingly use the modified linear format used by Kimball. Of course, the two media may be combined, as Keeton does in his latest book. ${ }^{33}$

\section{Feedback to Student}

As in the case of the programmed text, the computer-based exercises inform the student about the correctness of a response. Computer technology, however, allows for a greater degree of individualization in

30. Thomas D. Morgan, Future Interests (PLATO-Illinois 1977).

31. See Roger Park, Evidence (Casebook Version) (UMCC 1978); and his Evidence, supra note 24.

32. Joseph D. Harbaugh, Simulation on Lawyer Decision-Making (PLATO-Illinois 1977).

33. See Robert E. Keeton, Computer-Aided and Workbook Exercises on Tort Law (St. Paul: West Publishing Co., 1976). This book instructs the student to use the workbook for some problems (usually those that require narrative answers) and the computer for others. It is a carefully constructed attempt to take advantage of the strong points of each medium. 
the feedback provided than is feasible with a programmed text. Just as the computer has the capability to process a large number of correct and incorrect responses, it can give any of an array of preprogrammed messages as feedback to the student's response. The feedback message may relay only a judgment of correctness or incorrectness, or it may contain an extended explanation of what aspects of a response or pattern of previous responses are correct, partially correct, or incorrect. That is, the feedback can be made as informative as the author desires.

We noted earlier that it is this informative nature of the feedback together with the learner's active participation that make these programmed instruction approaches effective for the learner. While the computer, in principle, cannot provide feedback different from what is possible in a programmed text, the fact that a larger number of possible feedback messages can be stored clearly distinguishes it from the programmed text. Because of its matching and processing capacities, the computer can provide the intended feedback efficiently and conveniently.

Unlike programmed text, the computer can also provide the student with automatic reports on his score or on the answers that other users have given to particular questions. Almost all the exercises use some sort of scoring system that is displayed to the student. The scores are not used to calculate a course grade (the temptation to cheat would be very high) but to increase motivation. Some exercises give the student the option of not being scored. In a few cases the student is given an evaluation at the end of the exercise that tells him how he has done in comparison with others who have taken the exercise. In Keeton's Decisions Before Trial exercise, the computer will collect responses from students, lawyers, and judges using the exercise, categorize those responses, and give users information about how each group answered particular questions.

\section{Feedback to Authors and Instructors}

Several exercises take advantage of the computer's capacity to collect information about student answers. This information can be useful to both instructors and authors.

Instructors can use the information in classroom teaching-for example, to concentrate on areas that gave students difficulty. They can also use the material to check on student progress and be certain that students have completed assigned exercises on schedule.

Authors can use computer-provided information in revising exercises. They can write complex branches for answers that are frequently 
given. They can eliminate or rewrite questions that are too easy. They can rethink their positions on questions that prove difficult to students. Seeing that a large number of students have chosen a "wrong" answer to a certain question may cause the author to decide that the answer is not so clearly wrong after all. Authors can also use data about student answers to improve the computer's capacity to recognize a broad range of free-language answers. The computer can report answers that authors did not expect. For example, suppose that the author has asked the question "Why do you say the objection should be sustained?" and has programmed the computer to recognize responses such as "leading," "conclusory," "hearsay," etc. If the computer reports that some users have answered "no foundation" (an answer that the computer has not been programmed to recognize), then the author can have the computer programmed to respond to that answer. The computer can also be used to poll the students about the exercise, e.g., to administer a questionnaire or ask students to type in comments about an exercise.

\section{Ability to Generate Questions}

The computer can, within limits, generate its own questions and evaluate students' answers to them. This feature can be a time-saver for CAI authors.

To give a simple illustration: Suppose that a teacher was preparing an exercise designed to drill elementary school students in addition. The instructor could, if so disposed, write individual problems, calculate the answers, and store each answer to each problem in the computer. However, it would be simpler to program the computer to generate random numbers to be added by the students. If the computer was also programmed with rules for adding figures, it could tell students whether their answers were correct without requiring the author to compute the answer to each problem. Moreover, it would not be necessary to store each answer in the computer's memory.

Some of the law-related CAI, such as Keeton's Computer-Generated Intent exercises and Morgan's Future Interest exercise use this capacity. ${ }^{34}$ The randomly generated portion of the Future Interest exercise has been described as follows:

34. See Robert E. Keeton, Computer-Generated Intent Exercises (UMCC 1977); Morgan, supra note 30. Other exercises using the random-generation capacity include Jane Kelso \& Charles Kelso, Counselling Programs (PLATO-Illinois 1977), and Peter B. Maggs, Offer and Acceptance-Problem of Communication (PLATO-Illinois 1977). 
It consists of 8,000 randomly generated problems, each of which presents the question of the present interest created, the future interest created and the interest if any retained by the grantor. These questions are generated, not by having 8,000 separate questions in the machine, but by having what are in effect four spins of a roulette wheel. The first two merely generate neutral terms, one the verb ("grants, bequeaths," etc.) and the other the name of the item given (Blackacre, Greenfields, Park Place, etc.). The next two, however, each generate one of the twenty potential items of significance. The first generates a clause from which the student is to deduce the present interest that has been created. The second generates a clause from which the student can conclude the future interest which has been created. In short, any of the twenty clauses describing A's interest can be matched with any of the twenty clauses describing B's interest. That makes for a practical total of 400 situations that can be posed to the student. ${ }^{35}$

Keeton's computer-generated exercises follow a similar pattern of constructing phrases from randomly generated elements. For example,

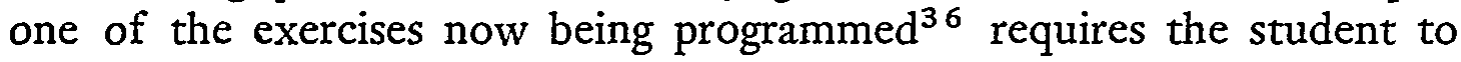
decide whether to object to jury instructions on the issue of the intent necessary to constitute battery. One of the jury instructions that the computer will generate is:

Long had the state of mind required for a prima facie showing of battery on Martin if Long, when acting, was substantially certain of accomplishing Long's purpose that the car door would strike Martin in a way that would be offensive to Martin.

The above sentence was generated randomly by having the computer choose segments from a selection of phrases supplied by the author. The sentence consists of four segments, as follows:

(Long had the state of mind required for a prima facie showing of battery) (if) (Long, when acting, was substantially certain of accomplishing Long's purpose that) (the car door would strike Martin in a way that would be offensive to Martin.)

In composing a question, the computer will choose randomly from the available choices a word or phrase to go in each of the segments set off by parentheses. For example, it has six possible phrases for segment three, as follows:

1. ... it was Long's purpose that ...

2. ... Long knew it was substantially certain that ...

35. See Maggs \& Morgan, supra note 20 , at 142.

36. This exercise is tentatively entitled The Case of Martin and Long. It is now being programmed on the University of Minnesota computer. 
3. ... Long, when acting, was substantially certain of accomplishing Long's purpose that...

4. ... it was substantially certain that ...

5. ... it was Long's desire or purpose that, or Long believed it was substantially certain that...

6. ... Long believed it was substantially probable that ....

Phrases 3, 4, and 6 introduce errors into the instruction, and the computer has been programmed to require that the student identify these errors whenever they appear. Additional errors can be introduced in other segments, or what would otherwise be an error can be cured by language in a later segment. On occasion, an error may appear only when two segments are used in combination. The computer has been supplied with a set of rules for determining which segments, alone or in combination, produce an erroneous instruction and what types of error appear in each possible combination.

The computer's capacity to generate its own problems is exciting, if only because it is unique to the computer and cannot be duplicated in written text. Moreover, to the extent that the arithmetic comparison holds, it should allow authors to produce programs in limited time that can be used indefinitely by students.

Random generation may not always be a labor saver for authors. Sometimes it is more difficult to arrange questions in a fashion that facilitates random generation than to write each question separately. To the extent that random generation is a labor saver, it will be so because it permits authors to avoid the necessity. of considering the answer to each possible question separately, as in the case of problems in arithmetic. For this reason, the technique seems most easily adaptable to problems that are analogous to problems of mathematics. Both the Morgan Future Interest exercise and the Maggs Offer and Acceptance exercise involve rules of this nature. With regard to both, the authors cite the "mathematical" nature of the rules as one reason for choosing the subject-matter area:

[F] uture interests is one of the most mathematically oriented of legal concepts and thus is significantly easier than other areas in which to develop a workable, practical program.

... The traditional "mailbox" rules [of offer and acceptance] have a rather fixed and mathematical character which makes them considerably easier to deal with than the rules in a more dynamic and uncertain area of the law. ${ }^{37}$ 
Only a small segment of what we teach in law school deals with rules of a "fixed and mathematical character." Indeed, many teachers spend time disabusing students of the notion that such rules are the primary subject matter of the law. Undoubtedly some drill in this sort of rule is useful, but it can only form a small part of law teaching. And when we go beyond the "mathematical" rules, the random generation of problems-though not impossible-becomes somewhat harder, and the writing of individual problems may be as easy as composing meta-rules for the computer to follow.

Random generation of problems has other consequences as well. If problems are generated and ordered in a purely random fashion, there is no control over either sequencing or repetition. The student may receive difficult problems again and again; he may never reach certain types of problems; he may be flooded with problems that he finds easy and scarcely touch problems on which he needs remedial work. These difficulties can be resolved by programming the computer with rules about repetition, remediation, and sequencing. However, creating these rules removes some of the labor-saving benefits of random generation and makes the writing of individual problems an alternative worth consideration.

So far, exercises using randomly generated questions have made relatively little use of branching. They do not present students with follow-up questions designed to test their understanding of the answers they gave, nor do the exercises present counter-arguments, ask students if their answers would be different if certain facts were changed, or do other operations characteristic of classroom dialogue. It would be possible to combine questions of this nature with random generation of portions of an exercise, but the current exercises do not do so.

\section{Audio-visual Capability}

The PLATO system has both animation and audio capacities: cartoon figures (or any other graphic displays) can appear on the screen and the computer can be programmed so that it will speak its answers. (It cannot, however, accept spoken responses from the student.) These features have been used occasionally in law exercises but do not make up an important part of any of those presently available.

Both the Minnesota and PLATO systems can be used in interface with movies or videotape-for example, to produce a "trial" at which the student sees actors perform the role of judge, jury, and lawyers. The student can be required to make decisions during the trial and communicate them to the computer. The computer could be programmed so 
that the student's decision controls the subsequent video presentation. So far, only limited use has been made of this capacity. ${ }^{38}$

\section{Capacity to Require Answers Witbin a Limited Time}

Computers can be programmed to require that the student answer within a limited time. For example, in a trial simulation exercise, the computer might require the student to object to an examining attorney's question within a brief period. If the student hesitated until the time limit had expired, the computer would proceed with the trial as if no objection had been made. This feature could add an extra dimension of realism to exercises that simulate situations in which lawyers are required to make quick decisions.

\section{B. Use and Misuse of the Computer's Capabilities}

\section{Getting Beyond Rote Memory}

Computers can perform many tasks that cannot be done with workbooks or texts. Because they offer an individualized approach to instruction, they hold out the promise of providing a more active learning experience than students receive in our oversized law school classes. The machine's capability of interpreting and processing a wide variety of learner responses and acting differentially upon various responses distinguishes it as a medium for instruction. The instructional environment provided by the computer can be made to resemble that of a tutor guiding a student through a learning sequence by providing feedback based on the student's response, providing remedial branches according to certain kinds of errors, and tracking the student through a process of analyzing and solving problems.

The most fundamental problem facing authors in their attempts to make adequate use of the computer's distinctive features is how to elicit performances from the student that reflect an attainment of an appropriate level of knowledge and skill. Clearly, "knowing law" is more than the ability to recall or to recognize terms, concepts, and other elements having to do with an area of knowledge. Also, "knowing" is more than forming terms, concepts, and elements together into a structure. To be sure, these are necessary aspects of "knowing," but beyond these,

38. Two exercises by Charles Kelso make use of this capacity. See his Lawyer Ethics (PLATO-Illinois 1977) and his Effective Use of Feedback in the Classroom (PLATO-Illinois 1977). 
"knowing" involves manipulating structures and processing new data within that structure to solve problems or otherwise perform appropriately.

Unfortunately, some of the current computer exercises, at least in their preliminary forms, seem to be aimed mainly at eliciting information from the student's rote memorization process. The exercises involve the student in application of law to facts in a straightforward and unchallenging fashion. ${ }^{39}$ We will illustrate this type of exercise with an example that, though hypothetical, demonstrates precisely the sort of computer instruction that is sometimes offered.

In certain exercises, the computer first offers an instructional message setting forth a rule of law, e.g.:

Under the venue provisions of 28 U.S.C. sec. 1391, a civil action wherein jurisdiction is founded only on diversity of citizenship may be brought only in the judicial district where all plaintiffs or all defendants reside, or in which the claim arose.

After the instructional message disappears from the screen, the student is given a hypothetical calling for a simple application of the rule, e.g.:

Smith, a resident of the District of Nevada, brings a diversity action against Jones, a resident of the District of Minnesota, and Williams, a resident of the Northern District of California. The claim arose in the Middle District of Alabama.

In which judicial districts would venue be proper?

Ironically, some of the capabilities of the computer that make it a unique instructional tool create a temptation to write this sort of question. First, the computer's ability to deal with free-language answers encourages authors to write questions with predictable answers. In the foregoing example, the computer could recognize almost every conceivable student answer and classify it as correct or incorrect if it were programmed to recognize the names of the states mentioned in the question. Secondly, the computer's ability to generate its own questions creates a temptation to ask questions that are subject to algorithmic programming. If the author wished, the computer could generate an endless number of venue questions like the one quoted. It could easily be programmed to substitute names of parties and states and to gener-

39. The present authors are among those who are guilty of producing such material. In 1974, Park wrote an exercise that was primarily a drill in black-letter law, and he was aided and abetted in this endeavor by Burris. The current version of this exercise is Roger Park, Drill on Code of Professional Responsibility (UMCC 1978). 
ate problems presenting all the combinations possible under the venue statute. Finally, the computer's scoring capacity creates a temptation to use questions that, like the one illustrated, elicit answers that can easily be classified as correct or incorrect.

Undoubtedly, memorization is part of law school instruction, perhaps to a greater degree than most law professors would care to admit. However, students come to law school with memorization strategies that are probably as effective as computer-aided instruction. If they do not, aiding memorization with CAI may actually impede the development of the type of strategies that would be useful to the students when in law practice they must learn and retain information without the aid of the computer. Since the computer is a fairly expensive medium, it would be desirable to use it to accomplish more complex learning objectives. We should want to use it to train our students in those skills that distinguish a lawyer from someone who has merely memorized rules-e.g., skills of analysis and synthesis of doctrine, reasoning by analogy, distinguishing cases, recognizing ambiguity, construing rules in light of rationale. And we might want to use it to train students in some of the practical skills that distinguish a practicing lawyer from an academic lawyer.

We do not mean to say, however, that it is never appropriate to use the computer for memory drills. Sometimes it is very important that students memorize rules and have them at their fingertips. For example, a trial lawyer (or student participating in a clinical program involving trial work) needs to memorize rules about evidence and professional responsibility because often there will not be time for research in the heat of a trial. In other fields, an author might decide that memorization of certain rules is an essential prerequisite for more complex analysis, and that, left to their own devices, students will not do the necessary groundwork. We are merely saying that memory drills should not be the primary goal of CAI, and that they should not be offered without careful consideration of alternative techniques of instruction.

One way of using the computer for complex instruction is through use of what we will call a tutorial dialogue between the student and the computer. The tutorial dialogue can be used to sharpen the same skills that law teachers seek to develop in the classroom. Of course, there are circumstances in which the computer-student interaction can never be as effective as dialogue between a good teacher and a student; while the computer can ask any question that a teacher can ask, the computer 
author must in some way predict the student's answer and instruct the computer about how to process it.

The greatest challenge that CAI authors must face is that of creating a valuable tutorial lesson within the constraints imposed by the requirement that student answers be categorized before they are given. Admittedly, this challenge can be avoided by simply having the computer ask the student to type in an essay answer and in response print out a preprogrammed model answer for comparison. However, the only advantage of a computer over a workbook in this situation is to force the student to respond prior to displaying the model answer. If the computer is to process an answer in a more useful fashion, the author must try to write questions that will elicit predictable answers. In doing so, some of the spontaneity and flexibility of classroom dialogue will inevitably be lost. Nevertheless, the computer has some countervailing advantages. Given our law schools' baneful student-teacher ratios, it is not possible for the teacher to have extended tutorial dialogue with each individual student. Certainly this is not possible to the degree necessary to assess the student's ability to analyze and synthesize legal doctrine and solve complex legal problems. The computer, on the other hand, can be available to the student at all hours and can demonstrate consistent patience and tolerance. Most teachers recognize that more attention to the individual learner could achieve greater effectiveness and for many students the computer can supply this needed attention.

Although the need to ask questions that elicit predictable answers is admittedly a handicap, several of the existing exercises indicate that this feature need not prevent the computer from being used for training in complex analysis. One example is Keeton's exercise on the Restatement's concept of intent. The background materials for this exercise identify six common imperfections in applying the concept of intent. The exercise asks the student to examine a list of assertions and identify which of the six imperfections, if any, is present in each assertion. As any law professor who has taken the exercise can attest, it involves much more than merely memorizing the Restatement's definition of intent. For example, it is one matter to understand in an abstract way that the Restatement embraces a subjective concept of intent and another to apply that concept by identifying the error in the following proposed jury instruction:

When he threw the water, Davis had the requisite state of mind for battery on Jones if it was apparent that some of the water would splash on Jones and that the contact would be offensive to Jones. 
Another area in which the fixed-answer format may be consistent with training in sophisticated skills is the application of evidentiary rules to trial testimony. Students and novice trial lawyers have great difficulty in applying abstract rules to actual testimony, even in instances in which the rule seems clearly to call for a given result.

Consider the hearsay rule. A student can easily memorize a definition of hearsay-e.g., "an out-of-court statement is hearsay if it is offered for the truth of the matter asserted therein, and is dependent for its value upon the veracity of the declarant." He can easily understand that there is no reason to treat an out-of-court statement as hearsay when it is offered for a purpose that in no way requires reliance upon the sincerity, memory, perception, or narrative ability of the declarant. Yet he will still be puzzled when asked to apply the rule in practice. Evidence professors have long realized this and have drilled their students in the concept in much the same way that a computer exercise might.

Even when dealing with evidence doctrines less formidable than the hearsay rule, students have a difficult time transferring knowledge about rules to application in a courtroom setting. For example, a student who has memorized the rule requiring that the proponent of testimony affirmatively show his witness's personal knowledge will still fail to see the defect of a direct examination that fails to establish that the witness was present when an event that is the subject of his testimony took place. An evidence exercise that asks students whether an objection should be sustained or overruled and subsequently asks them to choose a fixed-format justification requires the exercise of sophisticated skills.

The computer's capacity to engage students in continuing dialogue can be used to enhance the intellectual challenge of a computer exercise. For example, suppose that a student sustains an objection to testimony and then states, incorrectly, that it should be excluded as hearsay. The computer need not evaluate this answer immediately. It can continue with a question designed to get the student to reconsider his answer. For example:

Jill argues that the statement is not hearsay if offered merely for the purpose of showing that the hearer was provoked by it. When offered for that purpose, she says, the truthfulness of the declarant is of no concern.

In light of her argument, do you still maintain that the statement is hearsay?

In a similar fashion, the computer can insert an intermediate question challenging the student who has given a correct answer. For example, if a student correctly states that the declaration against interest exception applies, the computer can present a counter-argument: 
Plaintiff argues that when Joe acknowledged that he was indebted to Bill he was not making a declaration against interest, since it would be in Joe's best interest, as a businessman, to acknowledge just debts. Do you agree?

In the foregoing example, the student should realize that the rationale of the declarations against interest exception to the hearsay rule applies even if acknowledging just debts is in a businessman's best interest. If the student does not, then the computer will give a lesson in using the rationale of a legal rule to interpret the meaning of its language. Although, as Skinner argued, there may be some danger of implanting erroneous ideas through the use of such spurious arguments, they are necessary if the computer is to carry on a dialogue with the student by asking for disagreement or agreement with certain propositions. Otherwise, students would quickly come to realize that all counter-arguments by the computer were prompts designed to get the student to rectify errors, and students would not be actively engaged in considering whether they should agree or disagree with the arguments.

Sometimes the dialogue between computer and student over a particular question can go on for minutes or even hours. For example, in Park's Jurisdiction and Venue exercise, the student is initially asked to identify the forums in which a particular lawsuit could be brought. The computer then questions the student about assigned cases dealing with the nature of intent required for change of state citizenship. It comments upon the student's answers and periodically offers an opportunity for revision of the initial answers to the question about available forums. Many students do revise, apparently realizing that some of the points dealt with in the case law discussion affect the availability of diversity jurisdiction in the federal forums. Eventually, the computer gives its own opinion, with supporting reasons, about the answers to the initial questions.

Obviously, an exercise involving extended dialogue about complex issues offers neither immediate reinforcement for correct answers nor a learning environment in which the student is protected from error. However, as we indicated earlier, immediate feedback apparently does not contribute to instructional effectiveness. Moreover, few researchers would recommend that programs be designed so that students rarely make errors. A program should be difficult enough to challenge the student. However, student errors should not be allowed to go uncorrected, although the correction need not be done immediately. Furthermore, feedback about errors should be informative-i.e., it should normally provide more than a mere statement that the student's answer was "correct" or "incorrect." Finally, where the author provides a model answer, it is important that the student perceive the discrepancy 
between his response and the model response. Often it is a challenge to make the model sufficiently clear so that the student is capable of perceiving the discrepancy.

We cannot offer easy guidance to authors who want to produce computer exercises that are both programmable and challenging. However, authors who are experienced teachers may be able to find good subjects by reviewing their class notes and searching for areas where student answers fall into predictable patterns. Authors may also find it useful to focus on topics that have caused trouble because of differences in student aptitude. For example, classroom difficulties sometimes arise because a topic requires simultaneous consideration and close analysis of several statutes and cases. ${ }^{40}$ During class discussion, the student will need to refer to several authoritative sources, keep factual hypotheticals in mind, decide whether to take notes, listen to classroom dialogue, and at the same time attempt to formulate answers. During a computer exercise, the student can set his own pace, and the computer can be programmed to allow able students to proceed in large steps while filtering out students whose answers indicate that they are having difficulty. For the latter, the computer can direct attention to specific language in statutory provisions and case law and ask comparatively elementary questions about the interrelationship of these sources of authority before proceeding.

\section{Getting Beyond the Right and Wrong Answer}

Because many of the current computer exercises do require students to use sophisticated analytical skills, they are not subject to the objection that they merely require the exercise of rote memory. However, another objection goes deeper. To say that a pedagogical exercise is difficult, that it requires complex analysis, is not necessarily to say that it trains students in the intellectual operations required of lawyers and legal scholars. Law teaching that focuses on formal analysis can blind students to the other considerations that should be taken into account in legal decision making. Law is not mathematics, and teaching that treats it as if it were can be harmful, even when it engages the student in arduous mental gymnastics. In Jerome Frank's phrase, "[ $t]$ he law is not a machine and the judges not machine-tenders." 11 However,

40. For example, the question whether a specific act of misconduct is admissible against a criminal defendant may require simultaneous consideration of Federal Rules of Evidence 403, $404,405,406,608$, and 609 as well as case law construing those rules.

41. See Jerome Frank, Law and the Modern Mind 120 (New York: Brentano's, 1930). 
the use of a machine as an aid in teaching law need not lead to the teaching of mechanical law.

Two replies can be made to the contention that computer-aided instruction encourages a mechanical or formalistic view of the legal process. The first concerns the role of logical analysis of concepts and rules in the teaching of law, the second the ability of computer-aided instruction to offer students something more than exercises in formal analysis.

On the first point, it is probably fair to say that CAI authors would assign a somewhat more important role to formal analysis than would CAI skeptics. Admittedly, it is difficult to assign a position to skeptics because the merits of CAI have not been debated in legal literature. Conversationally, skeptics have expressed a variety of views, ranging from rule skepticism so extreme that it borders on nihilism ("there are no right and wrong answers") to the view that law teaching should focus mainly, if not exclusively, on situations in which pre-established rules do not resolve the problem presented to the decision maker.

Judging from their teaching materials, one may infer that CAI authors believe that students profit from examining situations in which logical analysis of rules leads to resolution of the legal problem presented. In many exercises we see a deliberate attempt to present challenging problems but, at the same time, to limit the factual situations presented so that the problems can be resolved by logical deduction from preexisting rules. That does not mean, however, that CAI authors are proponents of mechanical jurisprudence. To say that study of the logical implications of the Restatement's concept of intent or the formal structure of the rules of collateral estoppel is in itself a challenging and worthwhile activity is not to exclude the need for creative lawmaking when social policy demands it. It is only to say, as Cardozo did, that we should know where logic leads even though we may determine to abandon it for other guides. ${ }^{42}$ Indeed, understanding of the logical implications of legal concepts and rule structures gained through CAI can lay the groundwork for class discussion of creative lawmaking.

At any rate, criticism of CAI on grounds that it promotes a formalistic view of the legal process ignores its capacity to deal with legal issues that fall into the area of open texture-the area in which legal

42. "We must know where logic and philosophy lead even though we may determine to abandon them for other guides. The times will be many when we can do no better than follow where they point." Benjamin Cardozo, The Nature of the Judicial Process 38 (New Haven, Conn.: Yale University Press, 1921). 
rules do not clearly call for one result or the other-or that require the decision maker to take social policy expressly into account. The CAI author is not limited by the constraints that bind the author of a multiple-choice examination. Because CAI is an interactive mode of instruction, the author need not feel obliged to offer only questions that have clear right and wrong answers. The computer can present counterarguments, express qualifications, and recognize the validity of a variety of viewpoints. It can ask questions that require a student to recognize that it is not possible to arrive at a definitive answer by deduction from pre-established rules.

Computer authors differ in the extent to which they seek to present students with such questions. Some of the exercises (e.g., Morgan on future interests, Maggs on offer and acceptance $)^{43}$ never do so. In the Morgan exercise, one of the answers ("life estate," "reversion," "right of entry," "possibility of reverter," etc.) is always completely correct; no situations are presented in which the property interests of the parties are subject to reasonable dispute. In the Maggs exercise, there is always one correct answer to questions such as "Was a power of acceptance created?"

Other computer exercises do make an attempt to present questions raising debatable issues of law. Of course, there is no difficulty in having the computer ask such a question; the difficulty arises when it attempts to deal with the answer. One possibility is simply to require a "yes" or "no" answer and then tell the student that either answer is acceptable. However, this approach leaves the student with the justifiable idea that the computer is not really reacting to his comments and thereby takes some of the feeling of interaction out of the exercise.

Keeton has devised special words for dealing with debatable issues. To many of his questions, students are asked to answer either YES, NO, RABYES, or RABNO. Students are instructed that "RABYES means 'reasonable arguments for both positions and I prefer YES.' RABNO means 'reasonable arguments for both positions and I prefer NO.' "4 4

Park's Jurisdiction and Venue exercise contains a similar alternative-a "maybe" answer. Students are instructed that

The "maybe" answer should be used if you believe that a categorical "yes" or "no" is inappropriate. If more facts are needed before a decision can be made, or if sufficient facts are known but there are substantial legal argu-

43. Morgan, supra note 30; Maggs, supra note 34.

44. See the instructions on answering questions in Keeton, supra note 33, at v. 
ments on both sides, then you should answer "maybe." However, you should not base a "maybe" answer on conceivable but frivolous legal arguments or on factual possibilities which are unusual and improbable. ${ }^{45}$

The CAI author who uses the RABYES/RABNO vocabulary or the "maybe" answer has a variety of options in dealing with student responses. Suppose, for example, that the author believes that "maybe" is the best answer to a question. Arguments A, B, and C support a "no" answer; $X, Y$, and $Z$ support a "yes" answer; and the arguments are about evenly balanced. If a student answers "yes" instead of "maybe," the computer can tell the student to reconsider his answer, set forth argument $\mathrm{A}, \mathrm{B}$, or $\mathrm{C}$, and ask the student whether he has changed his mind. A student who does change can be presented with arguments in favor of his original position; one who declines to change can be presented with further arguments against it. Sooner or later, of course, the computer will tell the student the author's opinion.

Naturally, there will sometimes be a difference of opinion about whether "reasonable arguments" could be made on both sides. It may seem unduly mechanical for a computer to tell a student that the correct answer is "maybe" (or "RABYES"). However, this feeling can be reduced if the author maintains a reasonable degree of humility. The computer can note that not all lawyers would agree with the author and give students an opportunity to express disagreement by typing in a comment. These comments can be used in class discussion or in revising the exercise. In some cases, where the author wants to cling to his original position but other teachers have expressed dissent, the computer can give the students the option of seeing a rebuttal by the dissenters. (E.g., "In my opinion, the correct answer is 'no,' for the following reasons.... However, not everyone agrees. For a dissenting view, push 'd.' ")

The author can also deal with questions raising debatable issues of law by asking the student to justify the position that he has taken. In a few cases, it will be feasible to ask the student to type in an argument in his own words. This would be the case if the author believes that he can foresee that specific words will be used in any argument in favor of a given position. More often, the author will need to reduce the possible number of student answers with some restrictive instruction to the student. For example, when the issue involves interpretation of an opinion or statute, the computer could ask the student to identify language in 
the statute or opinion that supports his position. It could then respond by telling the student the author's view about whether the language supports his position, or by asking the student whether he wants to change his answer in view of other language in the case or statute, in view of certain distinguishing facts in the hypothetical case, or whatever. Alternatively, a student could be asked to identify language supporting both sides of a position, with prompts from the computer if he is not able to do so on the first attempt. CAI has some advantages over class discussion when this sort of close textual analysis is involved. The student can proceed at his own pace and take the time to examine and relate several sections of a case or statute before answering.

Alternatively, the author can use a multiple-choice format when asking a student to advance arguments for and against a position. Park's exercise entitled "Case Analysis-Baker v. Keck" contains one example:

$\mathrm{Q}-14$. It is 1978. You are trying to persuade a judge to endorse the rule that voting in a state conclusively establishes citizenship there for diversity purposes. Which of the following arguments should be advanced in support of this position?

1. The rule will discourage forum-shopping.

2. The rule will restrict diversity jurisdiction to cases where there is danger of state-court bias.

3. The rule will be easy to administer.

4. Baker v. Keck provides precedential support for the rule.

5. The rule will reduce the number of lawsuits.

[Answer with as many numbers as are appropriate.]

By techniques such as these, the author can attempt to reproduce some of the features of classroom dialogue. Obviously, the student's participation in the dialogue will not be as great as that of a student called on in class, but it will be greater than that of most of the onlookers. Also, of course, the computer author has one advantage over the classroom teacher-responses to student answers can be revised and sharpened in light of computer-provided information indicating whether feedback was helpful to students.

Certainly an excellent computer exercise could be constructed using only questions that are subject to a fairly clear "right and wrong" answer. Yet it seems preferable to include at least a few debatable issues of law, if only because that is so much of what we are concerned with in law school, and because otherwise students may get the mistaken impression that legal questions are usually as clear as those presented by the computer. However, it would be a mistake to concentrate solely on questions that raise debatable issues of law. The question with a clear answer lends itself more readily to branching, scoring, and certain other 
computer capabilities. Moreover, the debatable question tends to be the focus of law classes-even to the exclusion of others. Questions that fall in the area of open texture provide the most exciting material for class discussion. Every argument can be met with another. Questions that have "one right answer," even if they involve complex analytic steps, are somewhat less appetizing material for class discussion. These questions can usefully be asked by CAI, and the computer's capacity for feedback and scoring may actually make them more exciting than they would be in class.

In the foregoing pages, we have discussed the use of the computer for memory drills and for tutorial sessions. The first use takes advantage of the computer's capability for random generation and scoring but sometimes has questionable pedagogical value; the second use also takes advantage of the computer's capacity for a complex interactive dialogue and may, if properly used, replicate some of the best features of classroom teaching.

The computer can also be used for simulation exercises that place the student in realistic practice situations. Of course, either a memory drill or a tutorial session could be cast in the form of a simulation, in the sense that students can be told that they should assume the role of a lawyer. However, there is a category of simulation exercise that differs materially from either the memory drill or the classroom-like tutorial session.

In one such exercise the computer places the student in the role of a lawyer trying a case. ${ }^{46}$ The computer plays the role of the judge and rules upon the student's objections to testimony. It does not give reasons beyond those a judge would give, though after the trial is over it gives the student a diagnosis explaining the judge's reasons for the ruling. This type of exercise differs from the tutorial exercises we have described because it does not permit the same degree of complexity in legal analysis. On the other hand, it does offer something different from a memory drill. Acquiring the skill of objecting at proper points in a trial requires much more than the memorization of rules of evidence, particularly if some realistic time limitation is placed on the opportunity to object. Here again the computer may offer an opportunity for individualized instruction in lawyers' skills that cannot be matched except in a one-to-one encounter between teacher and student. 
Of course, simulation exercises need not be limited to trial tactics and evidence. They can include pretrial procedure, client interviewing, business planning, drafting, and a host of other subjects. The development of simulation exercises may be one of the most fruitful fields of computer-based instruction.

\section{MEASURING THE EFFECTIVENESS OF LAW-RELATED CAI}

Regular classroom use of law-related CAI began in 1973-74. Since then, three studies of CAI impact on law students' attitudes have been conducted, and there has also been some attempt to evaluate the impact on student performance. Our objective here will be to review the evidence gathered to date and, more importantly, to present the issues and concerns that need to be addressed in future studies of CAI impact. At this early stage in the development of computer-based instructional materials, this lack of studies of impact on performance is understandable and excusable. Most of the available programs have gone through only the initial stages of testing and revision. But the need for evidence showing the influence of CAI on the performance of law students must be met by law professors and educational researchers if the use of these materials is to be based on more than fashion.

\section{A. Impact on Student Attitudes}

One unpublished and two published studies have examined student reactions to the use of computer-based instructional materials. Nearly all students involved in these studies have evaluated them favorably.

In studies carried out in 1973 and 1974, Maggs and Morgan report that 93 percent of the students believed the computer (PLATO) was something more than a "gimmick" in legal education. ${ }^{47}$ From these same studies they report that only 7 percent believed the use of the computer was "dehumanizing." In comparing PLATO's "helpfulness" to casebooks and classroom sessions, they report that a minority of students in four different classes ( 8 percent, 18 percent, 17 percent, and 35 percent) believed PLATO to be "less helpful" or "much less helpful" than the casebook. Also, about 42 percent in each of the same four classes believed PLATO to be "less helpful" or "much less helpful" than classroom sessions. That is, a majority in each class believed PLATO to be as helpful or more helpful. Maggs and Morgan also report that about

47. See Maggs \& Morgan, supra note 20 , at $148,149$. 
90 percent of the students believed they could learn the subject matter of the two exercises (future interests or offer and acceptance) with PLATO and without any live classroom instruction.

In the second published report, student reaction was also favorable, although no statistical data are included. Henn and Platt report that student reaction to PLATO was enthusiastic and that an overwhelming majority would recommend using the materials again in courses. ${ }^{48}$

During 1976-77 attitudinal data were collected from 799 students who had used 1 or more of 12 Minnesota-based CAI programs made available over the EDUCOM Network; nine law schools were involved in this study. ${ }^{49}$ Across all law schools and programs, 97 percent of the students believed the computer-based exercises to be useful (extremely useful, 29 percent; very useful, 43 percent; somewhat useful, 25 percent; not useful, 3 percent). Of course, among the 12 programs the degree of usefulness as rated by students varied; for example, 3 programs (Evidence, Complaint, and Demurrer ${ }^{50}$ ) were rated extremely or very useful by about 90 percent of the students. It is noteworthy that these 3 most highly rated programs involve the most challenging and complex questions; some items have error rates as high as 30-40 percent. Each of the 9 other programs was rated extremely or very useful by more than half the students. Further, 89 percent agreed, and only 4 percent disagreed ( 7 percent were neutral) with the statement, "the program [exercises] should continue to be offered as a part of this course." Only 5 percent disagreed with the statement that "the program's responses [feedback] were informative." Students gave positive ratings of similar magnitude to other questions dealing with the clarity, enjoyment, and atmosphere for learning associated with these exercises. ${ }^{51}$

Clearly, the reports thus far indicate a positive student endorse-

48. See Harry G. Henn \& Robert C. Platt, Computer-Assisted Law Instruction: Clinical Education's Bionic Sibling, $28 \mathrm{~J}$. Legal Educ. 423, 435, 436 (1977).

49. Questionnaires were distributed to all students using the computer-based exercises at nine law schools as part of a pilot study conducted jointly by EDUCOM and the University of Minnesota's Consulting Group on Instructional Design. Tables showing the results of the analyses of the data from the 799 questionnaires returned are available from the Consulting Group on Instructional Design.

50. Roger Park, Evidence (Casebook Version) (UMCC 1977); his Drafting the Complaint (UMCC 1977); and his Demurrets and Judgment on the Pleadings (UMCC 1977).

51. It should be pointed out that these data were collected as part of a formative, rather than summative, evaluation study of the exercises on the EDUCOM Network. That is, the data were collected as feedback to the instructors and authors to aid in revising the design of the courses and programs. 
ment of computer-based instructional materials as resources for learning in law classes. While students view lectures and classroom sessions as being most useful, they also perceive CAI materials as being as useful as or more useful than the casebooks used in the courses. ${ }^{52}$ These results are similar to student ratings obtained in different subject matter areas comparing the value or usefulness of various other supplements to classroom teaching. ${ }^{53}$ That is, when students in other fields have been asked to rate the usefulness of instructors, teaching assistants, texts, workbooks, audiovisual materials, and computer-based materials, the teacher in the classroom is nearly always rated the most valuable aid for learning. Other aids, even when rated highly useful for learning, are ranked below the instructor. This observation should give reassurance to those law professors concerned about being replaced by the computer.

Of course, this very positive student endorsement must be viewed with caution. Many students were evaluating their first experience with computers, and the "newness" may account for some of the enthusiasm. Also, the use of the computer exercises introduced a change of pace or something different in the usual arrangement of course activities. However, despite the possibility that student ratings were inflated by these effects, it seems reasonable to conclude that the residual would remain positive. As use of computer-based instruction increases, we can expect more accurate measurement of students' perceptions of its usefulness.

\section{B. Impact on Student Performance}

Very little evidence exists about whether improvement in learning results from use of these exercises. While the students' and instructors' perceptions of usefulness and helpfulness of these exercises suggest such an effect, objective measures of improved performances due solely to the use of computer-based materials are, at best, weak. Such measures are difficult, if not impossible, to obtain in any direct manner. The

52. See Maggs \& Morgan, supra note 20 , at $150-51$. Similar results were obtained in an unpublished study involving the students in Professor Park's civil procedure course during November 1974. Tables showing the analyses of the data collected in an evaluation questionnaire are available from the Consulting Group on Instructional Design.

53. Studies of student ratings of various resources for learning were carried out by the Consulting Group on Instructional Design in a number of courses at the University of Minnesota in beginning German, calculus, and art history during the period from 1972 through 1977. Analyses of the data from these studies are available from the Consulting Group on Instructional Design. 
interactions of an almost unlimited number of variables make it impossible to isolate the exclusive effect of a lecture, a series of lectures, a text, casebook, or a computer program. This is not to say that we cannot seek evidence that computer exercises have a beneficial effect on student learning, but what evidence to collect and how to collect it present challenges of considerable complexity.

Both the Maggs and Morgan study and the Henn and Platt study report data that provide some evidence of beneficial effects of PLATO programs. $^{54}$ At Illinois in 1974, 56 students were divided into four groups of 14 each. One group had the PLATO program on future interests and no class, the second group had the program and two weeks of class, the third group had the program and three weeks of class, and the fourth group had three weeks of class but no PLATO program. On a 75-item, multiple-choice test given immediately following instruction, the students in the two groups who had both the program and the class performed significantly higher on the test than did students in the two groups who had only the program and only the class. ${ }^{55}$ While these data suggest that the computer-based program had a beneficial effect on the students' performance, the experimental design, as reported, does not show an isolated effect of the computer program. For example, the effect might be accounted for by differences in the time spent at study in the groups or in the higher motivation of students who volunteered to take the CAI exercise. Moreover, students using the computer program might have performed as well if they had used a text version of the program.

Henn and Platt report on a comparison of performances of a 1975 class that used no CAI with a 1976 class that used PLATO. ${ }^{56}$ Significantly higher scores on a take-home corporation law project were observed in the performances of the 1976 class than in the performances of the 1975 class. Again, these data suggest that there was a beneficial effect of the computer program on performance, but the program's effect cannot be isolated from a number of alternative explanations.

Of course, neither of the two studies was intended as a definitive demonstration of the computer as an effective instructional medium. Indeed, it would be extremely difficult to demonstrate conclusively any general effect attributable solely to the computer. Any study attempting

54. See Maggs \& Morgan, supra note 20, at 147; Henn \& Platt, supra note 48, at 434, 435.

55. See Maggs \& Morgan, supra note 20 , at 147.

56. See Henn \& Platt, supra note 48 , at $434,435$. 
to do so would need to take into account a multitude of variations in computer exercises and in the students taking them. These variables interact in ways that add many degrees of complexity to studies of effectiveness. For example, whether the student achieves a particular level of performance following the completion of a computer program depends on what subject matter and skills were to be learned; what form, organization, and sequence were used to present the subject matter; what instructions, activities, and feedback were given to the student; and what abilities, interests, and prior knowledge the student brought to the learning task.

The challenge presented to law professors and educational researchers concerned about demonstrating the impact of the computer for student learning effectiveness must focus on particular variables in particular contexts. "Laws" of learning do not exist that are sufficiently generalizable to guide the development and testing of a computer program (or any other learning aid, including lectures and textbooks) independent of the subject matter area, student characteristics, and achievement measures. ${ }^{57}$ With our present level of understanding of the processes involved in teaching and learning, any demonstration of instructional effectiveness must focus on the variables and arrangements within particular situations.

For example, whether or not a computer program is an effective aid for learning the subject of evidence depends on many variables. First, the organization and form selected for the presentation of concepts will have an effect. An instructional sequence might present concepts first in an organized, formal way followed by illustrations from which the student is to derive fuller understanding of the concepts. If computer-based instruction using this format produces test results that are better or worse than those derived from classroom instruction that begins with illustrations and moves later to general concepts, then the difference may be due to organizational structure

57. Recent statements of a number of experimental psychologists and educational researchers evaluating the fruitfulness of the social scientists' pursuit of laws of behavior over the past 30 years point out the discovery of unforeseen complex interactions among variables involving the individual and situation. See James Jenkins, Why It Is Hard to Move from the Laboratory to the Classroom: A Four-Pointed Problem, paper presented at the American Psychological Association annual convention, San Francisco, Sept. 1977 (manuscript available from the Consulting Group on Instructional Design); Lee Cronbach, Beyond the Two Disciplines of Scientific Psychology, $30 \mathrm{Am}$. Psychologist 116-27 (1975); Wilbert McKeachie, The Decline and Fall of the Laws of Learning, 3 Educ. Researcher 7-11 (1974); Russell Burris, The "Field Plot" Model for Instructional Research in Higher Education, 10 Educ. Psychologist 107-11 (1973). 
instead of to qualities inherent in the two media. Second, the directions, activities, and feedback that the instructor provides for learning the particular subject matter will produce differences. Third, the abilities, interests, and prior experiences brought by the student to the learning situation will influence learning. Fourth, and most important, the type of tasks, performance criteria, and assessment measures used to evaluate student achievement will influence any measure of effectiveness. Not only are the variables within each of these four areas important to consider in assessing effectiveness, but they interact in ways that make such an assessment extremely complex.

The studies by Maggs and Morgan and Henn and Platt referenced above fail to provide information about or show sufficient control of such variables. Therefore, these studies provide no more than a hint that the two computer programs were effective as used in the situations described. Future studies intending to demonstrate learning effectiveness of CAI in legal education should reflect consideration of a much larger number of variables.

It should be emphasized that a genuine examination of the computer as a medium of instruction is not an appropriate focus in an evaluation of effectiveness. Just as there can be effective as well as ineffective lectures and casebooks, there may be effective as well as ineffective computer exercises. The focus, therefore, must be in demonstrating the effectiveness of a particular computer exercise, in learning of a particular subject matter, with a particular arrangement of other learning aids (lectures, texts, etc.), and for a particular group of students. The question to be addressed in such an evaluation is not "Is the computer an effective instructional device?" but rather "Can the instructional effectiveness of the computer be shown in one or more contexts to a degree that warrants its use in legal education?"

\section{SUMMARY AND CONCLUSION}

The computer as an aid for learning and teaching offers the law professor many possibilities for new instructional designs. Indeed, the selection of what to present to the student is limited more by imperfect understanding of the critical variables involved in effective teaching than by restraints of the classroom, textbook, computer, or other technol-

ogy. Current uses of the computer show the feasibility of producing drills, simulations, and tutorials. The computer can ask the student for a response, process the response, and proceed differentially through a program of instruction according to features of the individual student's response. The student can practice applying rules, drawing inferences, 
and solving problems. The computer can provide feedback predicated on the student's response and can be programmed to present alternative branches through a program according to the characteristics of the student's responses. Finally, the computer can track a student through the process of analyzing and solving problems. Such instructional design possibilities can be challenging, even staggering, to the author and teacher.

Legal education is only beginning to make use of the technological capacities of these machines, and users have indicated that student reaction has been almost unanimously positive. The computer's novelty as a teaching aid and the current paucity of clear demonstrations of its effectiveness in legal teaching situations should urge caution upon anyone wishing to offer an unrestricted endorsement of the machine's instructional capabilities. For many, however, the expectations and faith associated with the development are great.

Over the past several years psychological and instructional researchers have directed increased attention toward the more complex issues and questions associated with effective teaching and learning. ${ }^{58}$ While no "cookbook" or simple prescriptions for making instruction effective are foreseeable from this effort, better hypotheses, research methodologies, advice, and guidelines relevant to carrying out and improving instruction are likely to become available. As a larger number of experienced law professors turn to the computer as a medium for instructional design, more effective use of the medium can be expected.

An important factor that will influence development and future use of CAI in legal education is cost. At present the computer-based exercises can be made available to law students at terminals connected to large time-sharing computer systems at costs from as low as $\$ 1$ an hour to more than $\$ 20$ an hour. Communication, terminal equipment, and pricing policies of the computer systems services are the sources of these cost variations. As has been true with most electronic devices during the 1970s (e.g., the hand calculator, video games), the CAI costs associated with equipment may be expected to decrease during the next few years. Eventually, it may be possible to offer several computerbased exercises appropriate for a single course and comparable to a course workbook at about the same cost as a workbook. That is, the

58. See Jenkins, supra note 57; Cronbach, supra note 57; McKeachie, supra note 57; Burris, supra note 57. 
cost of providing a student a library of programs in a course involving 10 or 20 hours of drills and problems may drop to about $\$ 5$ or $\$ 10$.

The quality, effectiveness, and success of CAI depend primarily on individual and collective support by law professors, who must find new and more flexible approaches to effective instruction. More is required than the mere introduction of new techniques and technologies in courses that are otherwise unchanged. No educational technologist can provide the needed expertise. It is the law professor who will need to develop the technique that will make the use of the computer effective in legal education.

\section{APPENDIX A:}

\section{Illustrative Excerpts from Charles D. Kelso}

\section{A Programmed Introduction to the Study of Law}

Part I: Case Skills (Indianapolis: Bobbs-Merrill, 1965)

In the first part of Kelso's book, the student is instructed to fill in blanks in partially completed sentences. The student then uncovers the author's answer, compares it with his own, and moves on to the next "frame." This part of the book requires the student to memorize a standardized vocabulary and to frame answers in the exact words sought by the author. In conformity with Skinner's theories about programmed learning, the book attempts to prevent errors by moving in very small steps. The following passage, from page 82 , is illustrative:

Permission to reprint from A Programmed Introduction to the Study of Law, Part I: Case Skills, by Charles D. Kelso, copyright 1965 by the Bobbs-Merrill Co., Inc., granted by the publisher. All rights reserved. 
TOPIC 3. A CASE IN COURT

\begin{tabular}{|c|c|c|}
\hline \multirow[t]{2}{*}{19} & \multicolumn{2}{|l|}{ A prosecution for burglary is a (_ } \\
\hline & \multicolumn{2}{|l|}{$\begin{array}{l}\text { A prosecution for burglary is a criminal } \\
\text { action. }\end{array}$} \\
\hline \multirow{2}{*}{20} & \multicolumn{2}{|c|}{$\begin{array}{l}\text { A criminal action is one kind of }(-(-) \text {, namely, one brought by a representative of } \\
\text { the }(\quad) \text { to redress a wrong against the public. }\end{array}$} \\
\hline & \multicolumn{2}{|l|}{$\begin{array}{l}\text { A criminal action is one kind of } j u d i c i a l \\
\text { proceeding, brought by the state. }\end{array}$} \\
\hline \multirow{2}{*}{21} & \multicolumn{2}{|c|}{$\begin{array}{l}\text { A judicial proceeding brought by one person against another is called a civil action. A } \\
\text { judicial proceeding brought by one person to recover damages from another who has } \\
\text { breached a contract is a ( }) \text {. }\end{array}$} \\
\hline & \multicolumn{2}{|l|}{$\begin{array}{l}\text { A civil action is a judicial proceeding } \\
\text { brought by one person against another. }\end{array}$} \\
\hline \multirow{2}{*}{22} & \multicolumn{2}{|l|}{ Divorce is a (ب). } \\
\hline & \multicolumn{2}{|l|}{ Divorce is a civil action. } \\
\hline \multirow{2}{*}{23} & \multicolumn{2}{|c|}{ A civil action is one kind of $\left(\__{-}\right)$; a ( ) action is another kind. } \\
\hline & $\begin{array}{l}\text { A civil action is one kind of judicial } \\
\text { proceeding. A criminal action is an- } \\
\text { other. }\end{array}$ & \\
\hline \multirow{2}{*}{24} & \multicolumn{2}{|c|}{ Civil actions and criminal actions are alike in that both are ( } \\
\hline & $\begin{array}{l}\text { Civil actions and criminal actions both } \\
\text { are judicial proceedings. }\end{array}$ & \\
\hline
\end{tabular}


Later in the book, vocabulary tests appear that require the student to make somewhat more extended responses. The following excerpt from page 294 is illustrative:

TOPIC 9. 1. VOCABULARY TESTS (remove mask)

B. Complete the following definitions.

(1) A rule of law is a intended to that is applied by and supported by

(2) A right is a

(3) A remedy is a

(4) A liability is a risk of being ordered by a judge or other government official to because of a that results in an

(5) A cause of action is an that gives the right to a

(6) A complaint is the filed by the in a

(7) A demurrer is a in which the denies that the in plaintiff's complaint

(8) An answer is a in which the seeks a favorable judgment by some or all of the or by alleging —_ or both.

(9) A reply is a

(10) A prima facie case exists when is admitted for that plaintiff is entitled to prove under the

(11) The burden of proof in civil cases is the of an unfavorable verdict and judgment if the fact-finder (whether judge or jury) decides that the evidence is and there is no for either party.

(12) Reversible error is error which

(13) A judicial opinion is a statement in writing by a judge of his or the court's explaining

(14) A decision is a determination by a of the to be taken in a

(15) When an appellate court reverses the judgment of a trial court, it authoritatively sets the judgment aside as a declaration of the 
Kelso has stated that one reason for this emphasis on memorizing a standard vocabulary was to make it easier for the students to compare their answers with the author's suggested responses when they reach the sections that require essay answers. The comparison would be easier because students would not need to decipher synonyms. 59

In the latter part of his book, Kelso sometimes presents questions that are similar to those used in law school classes and examinations. Obviously, students will have a higher error rate on these questions. Kelso indicates that these questions are consistent with Skinner's observations that "retention, skill and a high rate of response (i.e., 'motivation'), are most quickly achieved if standards for performance gradually are raised as reinforcement is shifted from a continuous schedule (every correct response followed by reinforcement) to an intermittent schedule (correct responses only occasionally reinforced)."60 However, it appears that, in the interest of presenting more challenging questions, Kelso partially departs from Skinner's views. The book's essay questions are typically followed by "suggested answers" written by Kelso. Hence, immediate reinforcement of correct answers continues, but there is a higher error rate than is tolerated in the first part of the book. A larger number of students receive negative reinforcement, something that Skinner's technique seeks to avoid. Perhaps negative reinforcement is inevitable in sophisticated law teaching.

The following excerpts from pages 555-56 are illustrative of the more difficult questions contained in Kelso's book:

TOPIC 16. EXERCISE 103

Several questions may help unravel the factors combined in Grill.

A. Apparently, plaintiff's theory in Grill, that he had to show a malicious act by defendant in order to recover, was based on his understanding of Miller. He had alleged maliciousness in his complaint and it was on this basis that he attempted to distinguish Morton. Did the court indicate whether or not this was a basis for distinction between the two cases?

(Yes/No).

B. Proceeding on plaintiff's theory that he had to show malicious conduct, the court said that plaintiff's complaint alleged no facts which would warrant such a characterization. Thus, the court left open the question of whether or not it would follow or extend the rule of Miller if maliciousness was pleaded and proved.

In addition to dealing with the question presented in terms of plaintiff's theory and the Ohio mental distress cases relevant thereto, the court turned to another source of authority to reach its holding that the complaint did not state a cause of action. The court quoted from the Restatement of Torts. By re-scanning this quote and the remainder of the opinion after the quote, determine whether the court was responding to the entire rule as there stated, or to only a portion. Write all of the words of the rule to which you think the court was responding.

59. Telephone conversation with Charles D. Kelso, Oct. 11, 1977. 1977.

60. See Kelso, supra note 4, at iii; telephone interview with Charles Kelso, October 11, 
C. If in Grill, plaintiff had reasoned by analogy from the facts and the result of Rosnagle, how might he have stated his argument?

Sample Responses to Exercise 103:

A. No, the court did not indicate whether or not malice pleaded and proved was a basis for distinguishing Morton and Miller.

B. This is a question on which opinions may differ, and support found for each opinion in what the court says after the quote from the Restatement of Torts. In the opinion of the programmer, the court was responding (at least, primarily) to:

"A person who wantonly mistreats the body of a dead person ... is liable to the member of the family of such person who is entitled to the disposition of the body."

C. Reasoning by analogy from the facts and result in Rosnagle, the plaintiff could have argued that the plaintiff recovered damages in Rosnagle for foreseeable mental suffering caused by defendant's wrongful and intentional act, there being no showing that the act was malicious, since the conductor in good faith thought the coin was defective. In Grill, the defendant's act was wrongful and intentional, and plaintiff's suffering was foreseable. Hence, he should recover.

\section{APPENDIX B: Excerpt from Robert Keeton}

Programmed Problems in Insurance Law (St. Paul: West Publishing Co., 1972)

The following excerpt illustrates Keeton's branching format. Although some messages are given to all students, in many sections a student's route through the exercise depends on his answers to the questions. Problem $\mathrm{H}$ (p. H 1) provides one example:

Permission to reprint from Programmed Problems in Insurance Law, by Robert Keeton, copyright 1972 by West Publishing Co., granted by the publisher. All rights reserved. 
$\underline{\text { PROBLEM H }}$

Merchant sent from a foreign country to Ames by water a shipment consisting of widgets worth $\$ 250,000$ in the foreign country at the time of shipment. Because of unexpected competitive conditions, upon arrival the amount of widgets originally shipped would have been worth $\$ 150,000$ in Ames. The ship encountered exceptionally heavy weather, and when the cargo was unloaded in Ames it was discovered that the packaging of 30 percent of the widgets had been damaged, permitting salt water to reach them and render them completely worthless; the other 70 percent of the widgets were unharmed. Merchant had taken out a $\$ 100,000$ policy of marine insurance before the shipment was made. The policy contained no stipulation of value. What is Merchant's recovery from his insurance company?
(a) $\$ 75,000$.
(b) $\$ 45,000$.
(c) $\$ 30,000$.
(d) $\$ 18,000$.

Stop here and answer before proceeding.
If your answer was (a), turn to page H 2 .
(b), turn to page $\mathrm{H} 5$.
(c), turn to page $\mathrm{H} 8$.
(d), turn to page $\mathrm{H} 10$.

Suppose that the student gave answer (a) (a wrong answer) to problem H. The program directs him to the question on page $\mathrm{H} 2$, which reads as follows: 
[If your answer was (a)]

Which of the following was the reason for your answer?

(e) The widgets had a prime value of $\$ 250,000$ and Merchant lost 30 percent of them. Therefore he is entitled to recover $\$ 75,000$.

(o) Some other reason.

Stop here and answer before proceeding.

If (e), turn to page $\mathrm{H} 3$.

If (o), please state your reason on a separate sheet of paper, number the sheet $\mathrm{H} 2$, and deliver it to your instructor. you may place your name on the sheet or not, as you prefer. Return to page $\mathrm{H} I$ and reconsider your answer unless you prefer to put this problem aside.

If the student gives answer (e) on page $\mathrm{H} 2$, he is directed to $\mathrm{H} 3$, where he is given a further question designed to nudge him toward recognition of his error:

[If you agreed with (e)]

Marine insurance is customarily coinsurance. Does your answer give effect to this principle?

After answering this question, turn to page $\mathrm{H} 4$. 
After answering the foregoing question, the student is directed to page $\mathrm{H} 4$, where he receives informative feedback telling him why his answer was wrong, a suggestion for remedial reading in the text, and an instruction to reanswer the original question:

In choosing answer (a) because you agreed with proposition (e) you failed to take account of the fact that when the underwritten amount $(\$ 100,000$ in this case) is less than the prime value of the total property covered by the policy $(\$ 250,000$ in this case), marine insurance is coinsurance. If you do not understand this statement, read $\S 3.6(\mathrm{~b})$ and then return to page $\mathrm{H} I$ and reconsider the problem. If you do understand this statement and simply forgot to apply it, return directly to page $\mathrm{H} I$ and reconsider the problem. 